ARTICLE

DOI: $10.1057 /$ s41599-018-0081-0

\title{
Spatio-temporal evolutionary analysis of the township enterprises of Beijing suburbs using computational intelligence assisted design framework
}

\author{
Yi Chen', Zhijun Song ${ }^{2}$, Guangfeng Zhang ${ }^{3}$, Muhammad Tariq Majeed ${ }^{4} \&$ Yun $\mathrm{Li}^{1}$
}

\begin{abstract}
Township and village enterprises (TVEs) are market-oriented public enterprises under the purview of local governments based on townships and villages in the People's Republic of China. TVEs have become a vibrant part of the Chinese economy following the significant expansion during the 1980s reform period. In the mid-2000s, TVEs became an integrated part of Chinese industry after the property rights transition. In this study, we examined the dynamic behaviours of TVEs in the near-inner-outer suburbs; we simulated these behaviours using computational intelligence aided design framework, which embedded the micro-genetic algorithm with variable populations ( $V P \mu G A)$. Specifically, we assume that conditions follow development, which includes industry scale, industry profit, employees and district development; we then utilise the $\mathrm{VP} \mu \mathrm{GA}$ method to simulate the industrial structure and spatio-temporal evolution of the TVEs across seven industrial sectors and closely analyse the consequences of the transition. Our analysis results are consistent with actual observations, and a macro-level analysis showed that TVEs experienced defined scenarios. For Beijing, these scenarios are as follows: rapid development $\rightarrow$ chaotic development $\rightarrow$ steady development. The micro-level analysis showed that TVEs and labour have gradually formed a specific industry, a complex trend that evolved in both space and time. We determined the dynamic behaviours of the structures at micro-scales, meso-scales and macro-scales, clarifying the development of TVEs in the Beijing suburbs.
\end{abstract}

\footnotetext{
${ }^{1}$ School of Computer Science and Network Security, Dongguan University of Technology, 523808 Dongguan, China. ${ }^{2}$ Miyun Campus of Capital University of Economics and Business, 101500 Beijing, China. ${ }^{3}$ Sino-U.S. College, Beijing Institute of Technology (Zhuhai), 519088 Zhuhai, China. ${ }^{4}$ School of Economics, Quaid-i-Azam University, Islamabad 45320, Pakistan. Correspondence and requests for materials should be addressed to Z.S. (email: songzzjj@163.com)
} 
$\mathrm{M}$ odern suburban agricultural areas are located in metropolitan suburbs or economically developed areas, and are comprehensively influenced by urbanisation, industrialisation, and non-agriculturalisation development. Currently, the spatial structure of these areas is complex, with mesoscale features showing obvious spatial and temporal variability, while micro-scale features generally appear to evolve chaotically (Allen and Sanglier, 1981; Wilson, 2009; Clive and Tilzey, 2007). The current suburban socioeconomic system in China can be characterised as a hybrid system is based on both market economy mechanisms and regulation from the government. Under these two driving forces, the Beijing suburbs have strongly developed their non-agricultural production and socioeconomic service functions, as well as altering their ecological landscape features since 1978. However, these areas have significantly reduced their agricultural production function and strengthened their leisure and landscape construction functions. During the same period, the functions of the Beijing suburbs have experienced diverse internal spatial integration and variability, which has led to various developmental characteristics and trends within different geographical layers of the Beijing suburbs (Song and Liu, 2012a). Throughout the vast spatial area of Beijing $\left(16,411 \mathrm{~km}^{2}\right)$, these areas already have typical urban suburb characteristics. The inner suburbs of the agricultural areas have been affected by urbanisation, industrialisation, and non-agriculturalisation development; the outer suburbs have developed more slowly, though they have received strong support from the government (such as economic compensation and spatial development priorities). The industrial structure and development status of the township and village enterprises (TVEs) of the Beijing suburbs are representative of other large to medium-sized cities in China with large suburban areas (Zhang and Zhao, 2007).

The TVEs are market-oriented public enterprises under the purview of local governments based on townships and villages in the People's Republic of China. These areas have become a vibrant part of the Chinese economy after experiencing significant expansion during the reform period in the 1980s. The TVEs of Beijing suburbs began as rural township subsidiaries in the agricultural cooperative movement during the early days of the People's Republic of China. The first wave of rapid development occurred during the people's commune era, responding to the central government's call to promote agricultural mechanisation and rural industrialisation. The TVEs thrived from 1978 to 1989; they were largely dismantled between 1989 and 1996, after which they became an economic entity driven by the market economy (with a separate statistical investigation plan). Since the initiation of the policy of reform and opening-up in 1978, the TVEs, which are solely run by farmers and jointly controlled by the government, have been widely regarded as one of the major success stories of China's socioeconomic reform (Tan and Qu, 2011). The rapid growth of TVEs has been critical to the success of the country's transition to the market economy, because market competition is a significant factor that promotes TVE efficiency (Junichi, 2006; Louis, 1997). The Beijing agricultural area experienced rapid development prior to 1997, after which it gradually declined, but the development of TVEs has consistently been a fundamental driver of socioeconomic reform (Zhao and Wong, 2002). In particular, TVEs promote urbanisation, industrialisation and non-agricultural activities for farmers, as well as the sustainable development of the Beijing suburbs. TVEs currently have a massive impact on the development of the region at a variety of scales, so it is essential to understand the characteristics and tendencies of their development. A 2008 survey on Beijing TVEs has provided valuable data regarding the development of TVEs during the mid-2000s.
Currently, the non-agricultural functions of the Beijing suburbs have developed a spatial self-replicating features (Chen and Wang, 2013; Song and Liu, 2012a, b; Song et al., 2013a; Song and Zhu, 2013b). For example, urbanisation in the Beijing suburbs has fractal characteristics. In 2013, Chen and Wang studied the multifractal spectrums of Beijing's the spatio-temporal development indicates the city's spatial structure can be loosely divided into three layers from the downtown to its suburban, i.e., (1) City centre-due to overfilling of space, the fractal structure of highdensity regions is degenerated; (2)Suburban-due to the spatial constraint of urban growth, the scaling properties of the lowdensity regions become disordered;(3) the change extents of fractal parameters become narrower with the passage of time as the city is filled to capacity (Chen and Wang 2013). In 2018, Huang and Chen's paper has compared two ordinary least squares (OLS)-based approaches for estimating urban multifractal parameters (Huang and Chen, 2018). In particular, significant changes have taken place in the industrial structure of Beijing's suburban areas, and these changes directly impact the micro- and meso-scale evolution of these areas. The development of non-agricultural production functions, especially TVEs, is relatively complex, including stages of prosperity followed by decline around 1997. On the whole, significant changes in the social-economic base have taken place, and the rural landscape integrates both modern and traditional models.

The background discussed above suggests that it is important to understand and assess the development of Beijing TVEs. Specifically, we aimed to analyse, under various scenarios, the spatial structure of TVEs in Beijing, their employees (through industrial structural simulation), and their spatial states (through regional development simulation). One distinguishing feature of this study is that we examined TVEs in 13 counties using a microgenetic algorithm with variable populations (VP $\mu \mathrm{GA})$, which will be embedded into the computational intelligence assisted design (CIAD) framework (Chen and $\mathrm{Li}, 2018$ ), to construct and optimise the TVEs quantitative model. Then, it allows us to examine the dynamic behaviour of the collaborative industrial development in the region and understand the rural-urban evolution in the Beijing suburbs.

The paper is organised as follows. Section 'Introduction' gives an introduction to the development of the Beijing suburbs; Section 'Research background' introduces related literature; Section 'Methodologies' discusses the methodology used in this study; Sections 'Industrial structure simulation' and 'Regional development simulation' describe the simulations of the industrial structures and regional development using VP $\mu \mathrm{GA}$ (which aimed to numerically reflect the regional development process) and compare the results with previous studies.

\section{Research background}

Geographical scope of the Beijing suburb area. Beijing is divided into 4 functional areas based on their development, shown in Fig. 1: (1) the core capital, a built-up area that includes Dongcheng, Xicheng, Chongwen and Xuanwu; (2) the urban function expansion area (inner suburbs), including Haidian, Chaoyang, Fengtai and Shijingshan, which currently includes some agricultural areas; (3) the new urban development areas (mid-suburbs), including Tongzhou, Shunyi, Changping, Fangshan and Daxing, which have been rapidly urbanised and played a major role in shifting the agricultural population towards nonagricultural activities. These areas are currently engaged in modern agriculture; (4) the ecological conservation area (outer suburbs), including Mentougou, Huarou, Pinggu, Miyun, and Yanqing, which are involved in developing an eco-economic 


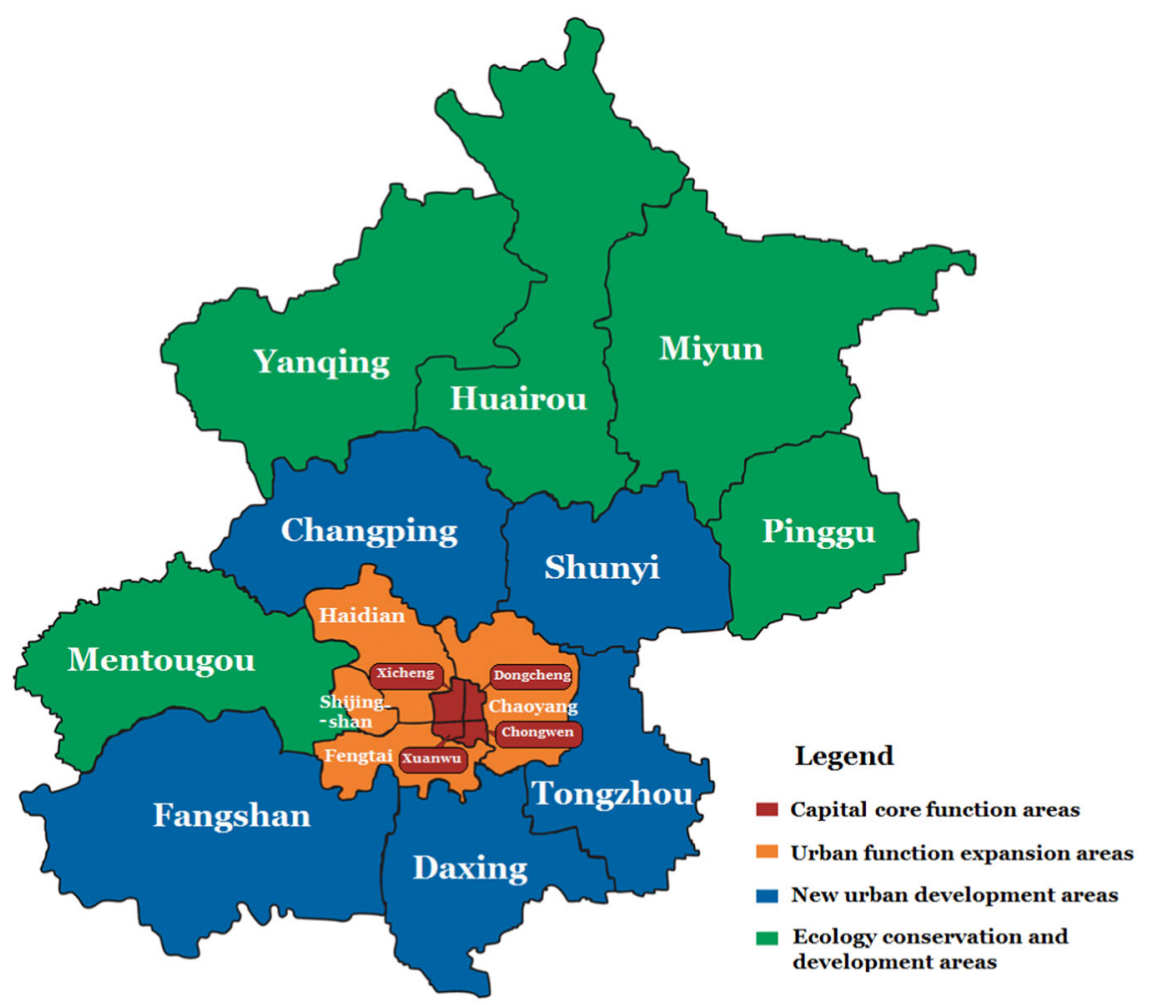

Fig. 1 Sketch map for the development plan of functional zones in Beijing

system featuring green agriculture, ecological industry and recreational tourism. In these areas, priority is given to cultivating a sound eco-conservation system and encouraging the local residents and industries to migrate to newly developed towns. The core capital is the major area that attracts rural labour, which can be confirmed using spatial analysis. This study did not incorporate agricultural activities because Shijingshan mainly includes non-agricultural activities. Therefore, the Beijing suburbs assessed in this study include the inner suburbs, mid-suburbs and outer suburbs. In total, these suburb areas encompass 13 counties: Chaoyang, Fengtai, Haidian, Fangshan, Tongzhou, Shunyi, Changping, Daxing, Mentougou, Huarou, Pinggu, Miyun, and Yanqing.

Macro-scale development of Beijing's suburbs. To assess development during the first ten years of the 21 st century, the 13 counties in the Beijing suburbs were examined by Song and Liu (2010, 2011) using principal component analysis (PCA) and cluster analysis. The results indicated that the three inner suburban counties have experienced similar macro-scale development: they developed rapidly, are well-developed economically, and former agricultural areas now present non-agricultural features. The five outer suburb counties experienced slow development and still host small-scale agriculture. The five mid-suburban counties all transitioned into urban areas with intermediate economic development, following similar development trends. Changping could be characterised by a suburban model. The diversity in the spatial variation among these counties is fundamentally driven by urbanisation, industrialisation and nonagriculturalisation in Beijing suburbs. PCA can significantly reduce the size of features to retain the most critical information for determining the macro-scale development of Beijing suburbs and providing a rough description of the overall status. However, the analysis does not include detailed information that is important to answering the next research question: what is the transfer mechanism that defines the shift in status of the Beijing suburbs? To answer this question, we simulate the development of the Beijing suburbs under various conditions to examine the mechanisms driving regional development.

Micro-scale and meso-scale economic development of Beijing's suburbs. The Beijing suburbs currently show post-industrial characteristics (Meng and Zhang, 2008). TVEs play a crucial role in the transformation from a rural to an urban economy, the integration of urban and rural functions, and the changes in quantity, benefits and income, and distribution of TVEs and their employees (Louise and Peter, 2008). Additionally, the incomplete nature of spatial agglomeration means that the TVEs in the Beijing suburbs have remarkable meso-scale features, which rise beyond a simple agglomeration of micro-scale characteristics (Liu and Zhu, 2006). These meso-scale features are largely due to the effects of county-level government spatial planning. Since the 1980s, the TVEs in the Beijing suburbs have been actively expanding in breadth and depth, and farmers have been able to improve their production and living conditions given the external economic externalities. The coordinated development of TVEs and farmers reflects the spatio-temporal processes of industrial innovation, urban expansion and labour force migration. In the Beijing suburbs, there is consistency between individual microscale development (e.g., the economic selection behaviour of enterprises and farmers) based on utility maximisation and macro-scale spatial development (e.g., at the county level) based on entropy maximisation. However, some TVEs have been impacted by large and medium-sized enterprises due to the limitations associated with technology, management strategies, economic scale and other factors after the mid-1990s, when the overall development scale and speed stabilised. The development of TVEs in 2007 to 2008 became more regular and was not influenced as strongly by sudden factors. This is an important reason for using $\mathrm{VP} \mu \mathrm{GA}$ in this study. 


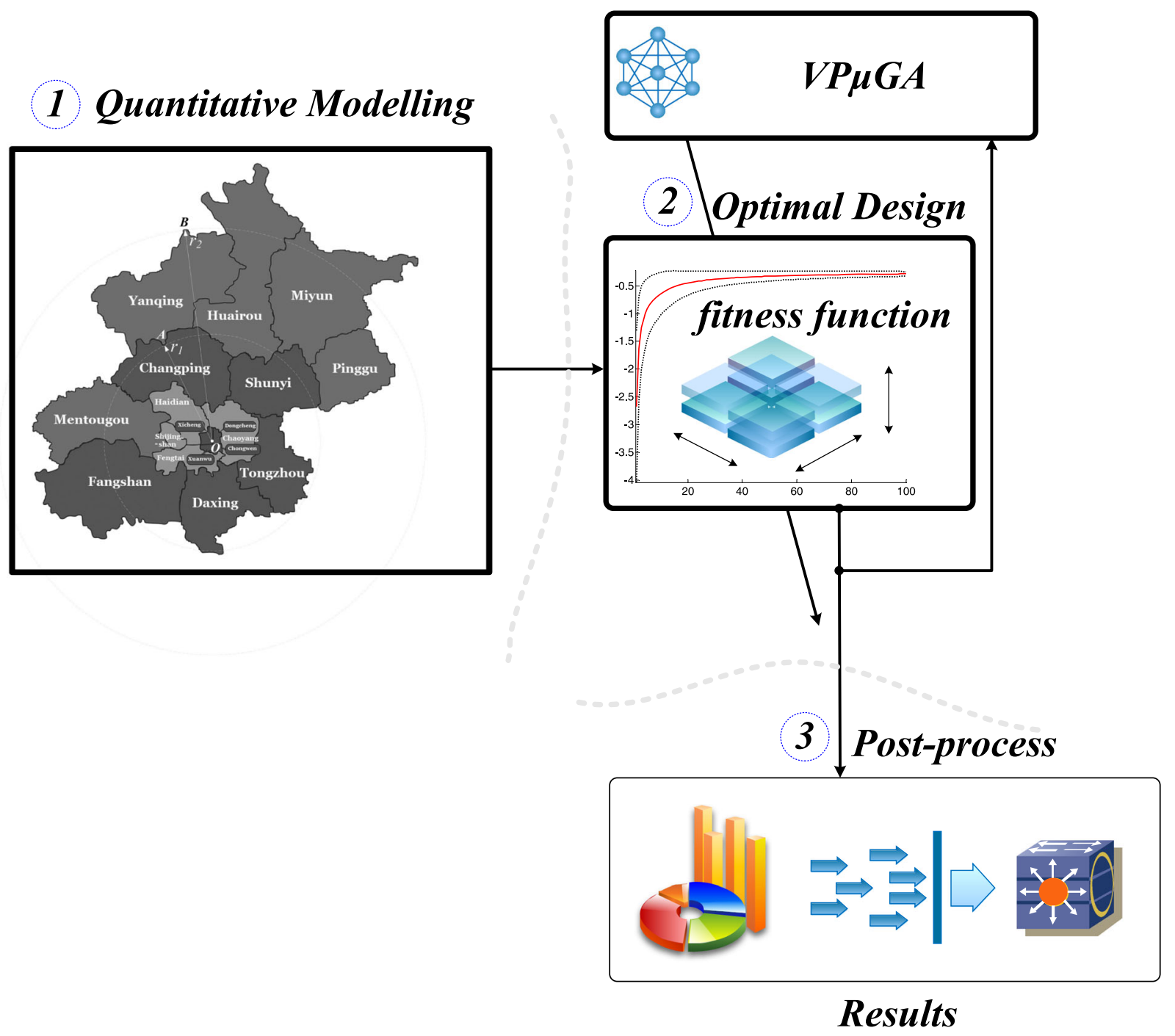

Fig. 2 Computational intelligence assisted design framework

Agricultural and non-agricultural sectors. In this context, the term 'agricultural sector' indicates agriculture-related enterprises that focus on the post-processing and large-scale production of agricultural and related products. These are market-oriented industrial enterprises that differ from traditional agriculture. Conversely, in this study, the term 'non-agricultural sector' refers to non-agricultural production-based industries.

\section{Methodologies}

Computational intelligence assisted design (CIAD) framework. Computational intelligence $(\mathrm{CI})$ is a set of nature-inspired approaches which offers a wealth of capability for complex problem solving. Compared to the traditional optimisation methods, CI does not need to reformulate the problem in order to search a non-linear or non-differentiable space. Another advantage of the $\mathrm{CI}$ is its flexibility in formulating the fitness function which can be expressed as a function of the system output. This feature is particularly appealing if an explicit objective function is difficult to obtain. As given in Fig. 2, the optimisation process can be shown in three steps as following:

Step 1: is the quantitative modelling under specific conditions for spatio-temporal evolutionary analysis of the township enterprises of Beijing suburbs.
Step 2: defines the fitness functions according to the objectives defined by the quantitative modelling, and performs the optimal design using the $\mathrm{VP} \mu \mathrm{GA}$ algorithm.

Step 3: produces the final results and completes the postprocessing tasks. More specifically, this step reports the optimal solution, analyses and visualises the results, and presents the recommendations to policy makers.

VP $\boldsymbol{\mu G A}$ algorithm. Genetic algorithms (GAs) are a subset of CI inspired by Darwin's theory of evolution; following the survival of the fittest rule, they use an evolutionary random search method. These algorithms have been widely studied and applied to many fields. The term $\mu \mathrm{GA}$ refers to a small population genetic algorithm with re-initialisation, with a population size of three as sufficient to converge, regardless of the chromosomic length (Krishnakumar, 1989) (Goldberg, 1989). The basic $\mu G A$ involves three types of operators, selection, crossover and mutation, and thus it is an ideal research tool for many micro-economic and geographical applications.

The VP $\mu \mathrm{GA}$ was proposed to facilitate the calculation process, utilising a small population and a re-initialisation process along with the overall GA evolution process. The $V P \mu G A$ work-flow is shown in Fig. 3. There are two cycles in the work-flow: the 


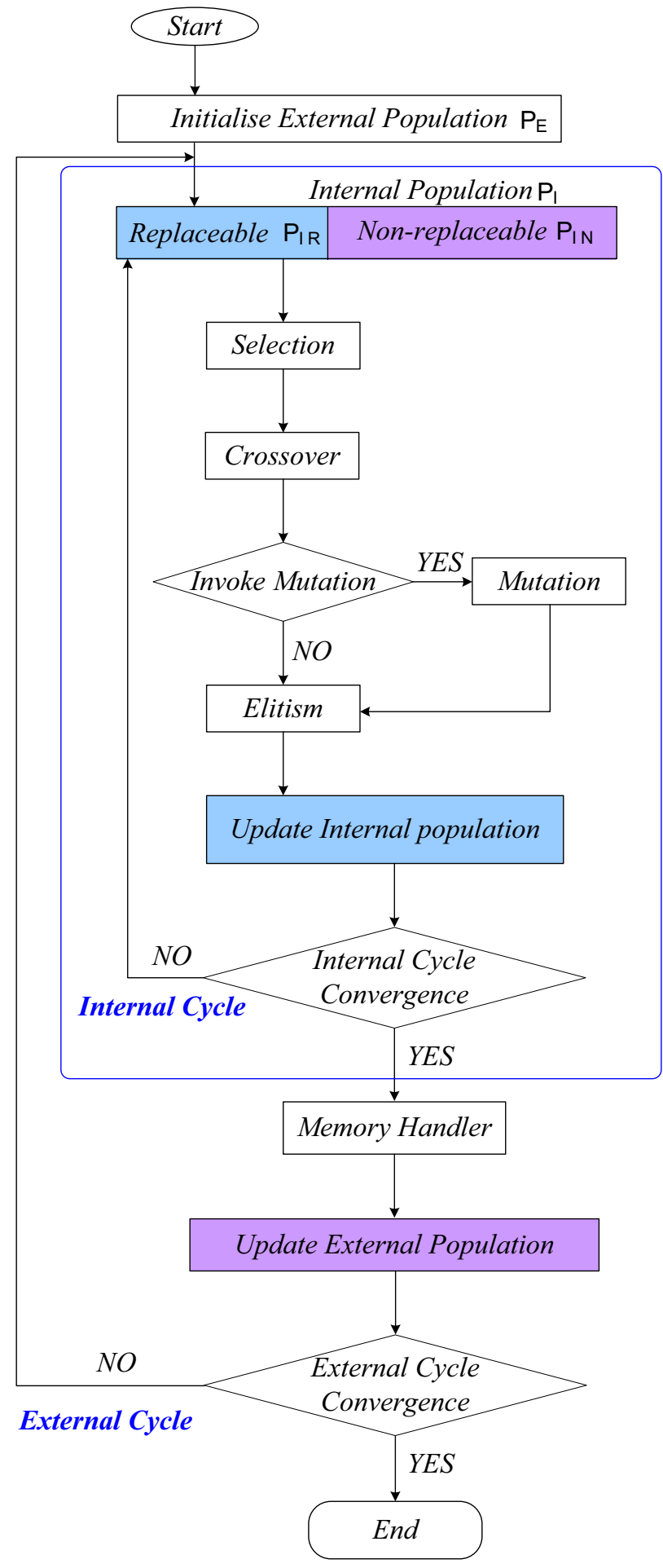

Fig. 3 The $\vee P \mu G A$ work-flow

'internal cycle' of the internal population $P_{\mathrm{I}}$ and the 'external cycle' of the external population $\mathrm{P}_{\mathrm{E}}$.

In the internal cycle, as in the basic $\mu G A$ process, the $V P \mu G A$ has three types of standard operators (selection, crossover and mutation) and an Elitism operator in the internal cycle. With an internal population $P_{\mathrm{I}}$, the programme will check to see if it meets the convergence criteria. As stated in Eq. (1), the internal population $P_{\mathrm{I}}$, which is used as the source of diversity of the internal loop, is made up of two sub-sections: the replaceable section $P_{\mathrm{IR}}$ and the non-replaceable section $P_{\mathrm{IR}}$. Equation (2) defines the size of $P_{\mathrm{IR}}$ at generation $\mathrm{t}$, which is calculated by the size of $P_{\mathrm{IR}}$ at generation $t-1$ plus the off-size of the replaceable section $\Delta P_{\mathrm{IR}}$ at generation $t-1$. That is, the current generation $P_{\mathrm{IR}}$ is decided by the previous generation's $P_{\mathrm{IR}}$ and $\Delta P_{\mathrm{IR}}$, in which the off-size replaceable population $\Delta P_{\mathrm{IR}}$ is proportional to the size of the original internal population $P_{\mathrm{I}}$, as is stated in Eq. (3), where $\lambda$ is a reproduction rate set by users.

In the external cycle, the $V P \mu G A$ updates the external population $\mathrm{P}_{\mathrm{E}}$ using the results from the internal population ${ }_{P I}$, and the external cycle meets the criteria of convergence, the $V P \mu G A$ terminates providing the overall optimal results. Briefly, the $V P \mu G A$ creates a population of solutions and applies genetic operators such as selection and crossover to find the results that best match the objective error limits (Chen and Song, 2012).

$$
\begin{gathered}
P_{\mathrm{I}}(t)=P_{\mathrm{IR}}(t)+P_{\mathrm{IN}}(t) \\
P_{\mathrm{IR}}(t)=P_{\mathrm{IR}}(t-1)+\Delta P_{\mathrm{IR}}(t-1) \\
\Delta P_{\mathrm{IR}}=\lambda P_{\mathrm{I}}
\end{gathered}
$$

Quantitative modelling of TVEs spatio-temporal evolution. Figure 4 introduces an 'input-feedback' that evolves to produce a new solution and finally converge on a specific data state that represents the optimal solution based on the original data, through the evolutionary and genetic mechanisms.

As shown in Fig. 4, we propose a specific conceptual framework of the spatio-temporal evolution of the TVEs. There are two parts of the analysis using $\mathrm{VP} \mu \mathrm{GA}$ :

- We first consider the macro-scale development of the Beijing suburbs, performing the 'Industrial development' simulations, including the evolution of 7 sectors, and the 'Regional development' simulations, including the evolution of 13 counties. These simulations are described in the 'Industrial structure simulation' and 'Regional development simulation' sections, respectively.

- Next, we examine the micro-scale development of the Beijing suburbs, which includes simulations of the status of TVEs (whether they enter or leave) and employee mobility. The latter involves four parameters: the number of enterprises in sector $\mathrm{i}\left(\mathrm{x}_{\mathrm{i}}\right)$, the average income of sector $\mathrm{i}\left(\mathrm{y}_{\mathrm{i}}\right)$, the number of employees in sector $i\left(z_{i}\right)$ and the layout between counties $\left(r_{i}\right)$.

The development of the Beijing suburbs shows that they have multiple functions, with their development guided by governments and their micro-scale activity driven by market mechanisms. The multiple functions of the Beijing suburbs and their spatial layout are shown in Fig. 5 (Section 'Regional development simulation'). However, there is no clear micro-scale spatial structure, while there is meso-scale coordination and macroscale stability. The interactions between micro-scale, meso-scale and macro-scale spatial structures (caused by the evolution and development of the TVEs) is unclear (Song and Liu, 2012a; Song et al., 2013a). In this paper, we employed VP $\mu \mathrm{GA}$ via CIAD framework to examine the micro- and meso-scale spatial states and evolution and empirically assess the issues presented in Fig. 5.

This study also emphasises the practicality of the $\mathrm{VP} \mu \mathrm{GA}$ method and its derivatives to economic geography research.

\section{Industrial structure simulation}

In this section, we analyse the industrial spatial change of the integration between employees, enterprises and industry sectors, as well as the characters and the driving forces of spatial development for each county at different development stages. Since the decline in 1997, the development of non-agricultural industries in 


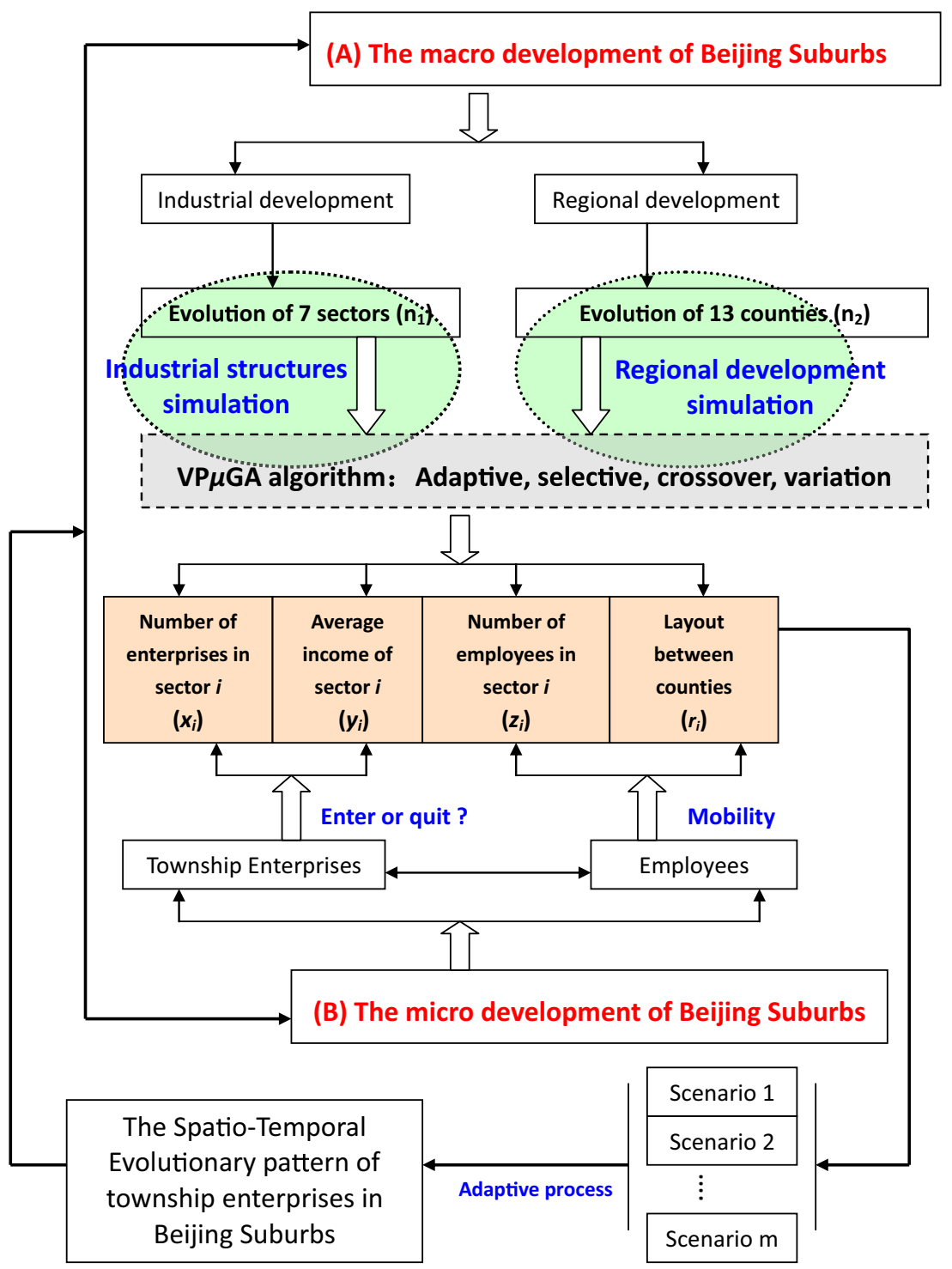

Fig. 4 A conceptual framework of the spatio-temporal evolution of the TVEs

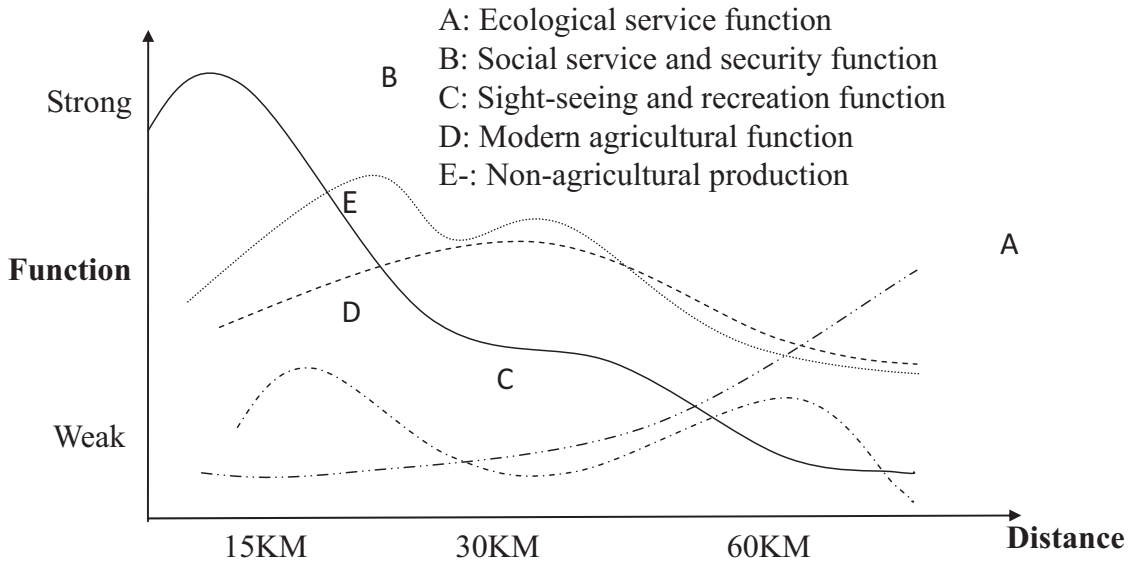

Fig. 5 The multifunctional transition pathway sketch map of suburban agricultural areas in Beijing

the Beijing suburbs has tended to be connotative, and new features emerged after 2000. The development of medium and small non-agricultural enterprises, particularly TVEs, has heavily depended on other sectors, including agriculture, industry, construction, transportation, wholesale, retailing, catering and household services, which are largely influenced by the market. These sectors reflect micro-scale socioeconomic activities and behaviours and the meso-scale states of regional development in 
Table 1 Basic statistics on TVEs of Beijing

\begin{tabular}{lllll} 
Item & Number of enterprises (unit) & $\begin{array}{l}\text { Persons employed } \\
\text { (person) }\end{array}$ & Total revenue (10,000 Yuan) & $\begin{array}{l}\text { Total profits (10,000 } \\
\text { Yuan) }\end{array}$ \\
\hline Total $^{\star \star}$ & & $\mathbf{1 , 3 9 6 , 6 0 2}$ & $\mathbf{2 9 , 6 7 0 , 8 4 4}$ & $\mathbf{1 , 6 4 4 , 9 6 5}$ \\
Agriculture & $\mathbf{1 6 6 , 9 1 1}$ & 33,939 & 221,004 & 19,904 \\
Industry & 3,926 & 658,055 & $14,767,412$ & 688,691 \\
Construction & 23,114 & 153,869 & $2,804,005$ & 187,547 \\
Transportation & 4,235 & 111,713 & $1,548,720$ & 144,379 \\
Wholesale and Retailing & 49,173 & 173,256 & $6,307,458$ & 233,858 \\
Retailing and catering & 14,634 & 84,769 & 806,530 & 71,383 \\
HS, OS and En & 22,266 & 162,658 & $1,943,627$ & 184,897 \\
\hline
\end{tabular}

Source: Beijing bureau for TVEs; ${ }^{\star}$ HS, OS and En denote Household Service, see the context for details

$\star \star$ Total values are from data source 1 , which is the sum of 7 sectors (major) + all other sections (minor)

Table 2 Average Economic Benefit ratio of TVEs in the 13 Suburban Counties of Beijing

\begin{tabular}{|c|c|c|c|c|c|c|c|c|}
\hline & $\begin{array}{l}x_{i} \text { computed } \\
\text { value }\end{array}$ & Variation (\%) & $\begin{array}{l}y_{i} \text { computed } \\
\text { value }\end{array}$ & Variation (\%) & $\begin{array}{l}z_{i} \text { computed } \\
\text { value }\end{array}$ & Variation (\%) & $\begin{array}{l}x_{i} \times z_{i} \\
\text { Scale }\end{array}$ & $\begin{array}{l}r_{i} \text { computed } \\
\text { value }\end{array}$ \\
\hline Agriculture & 4,808 & 122.472 & 231,751 & 104.863 & 13,118 & 38.651 & 0.473 & 54.81 \\
\hline Industry & 20,020 & 86.614 & $22,068,098$ & 149.438 & 959,669 & 145.834 & 1.263 & 45.64 \\
\hline Transportation & 2,093 & 49.422 & $1,764,976$ & 113.964 & 121,728 & 108.965 & 0.539 & 35.43 \\
\hline $\begin{array}{l}\text { Wholesale and } \\
\text { retail }\end{array}$ & 63,811 & 132.696 & $6,563,748$ & 104.063 & 175,249 & 101.150 & 1.342 & 3.82 \\
\hline $\mathrm{HS}, \mathrm{OS}$ and En & 23,810 & 106.934 & $1,219,870$ & 62.763 & 159,936 & 98.327 & 1.051 & 9.43 \\
\hline
\end{tabular}

the Beijing suburbs. A survey of TVE development was executed by the Beijing Municipal Bureau of Statistics in 2008. Industrial activities were divided into the seven sectors mentioned above (Table 1).

Assumptions and model specifications. The aim of this section on industrial changes was to examine whether the profit of TVEs was only related to a specific industry, and to determine whether there was socioeconomic coupling among counties. The assumptions and model specifications are as follows:

(i) The TVEs of Beijing suburbs have invested in 7 sectors, including agriculture (profit per capita: RMB 5,900 yuan), retailing and catering (8,400 yuan), industry (10,500 yuan), household services (11,400 yuan), wholesale and retailing $(13,500$ yuan), transportation (12,900 yuan) and construction (12,200 yuan).

(ii) The average profit of TVEs among the 7 attractors was RMB 50,700 yuan (agriculture), 298,000 Yuan (industry), 442,900 Yuan (construction), 29,400 (transportation), 48,600 yuan (wholesale and retailing), 48,800 yuan (retailing and catering) and 83,000 yuan (household services). Based on (i), the average number of employees was 8.64 (agriculture), 28.47 (industry), 36.33 (construction), 2.27 (transportation), 3.60 (wholesale and retailing), 5.79 (retailing and catering) and 7.31 (household services). The total number of employees was approximately 1,396,602.

(iii) TVEs are for-profit enterprises and can enter or leave based on the quantities of enterprises. Therefore, the maximum total profit of every industrial sector remained unchanged, amounting to RMB 199.04 million (agriculture), 6,886.91 million (industry), 1,875.47 million (construction), 1,443.79 million (transportation), 2,338.58 million (wholesale and retailing), 713.83 million (retailing and catering) and 1,848.97 million (household services).
The enterprises compete with each other and adapt to the conditions. The above industry attractors finally took shape through the coupling of industry profit and labour mobility.

Using the model with these specifications, $V P \mu G A$ was utilised as a tool to simulate the spatio-temporal evolutionary process of TVEs in the Beijing suburbs.

The fitting process of the 7 industry sectors during development was related to the income of investors (enterprises) and employees and the spatial distance. To estimate the industrial structure reflected by the enterprises and employees in the 7 industry sectors of the Beijing suburbs, the following objective function was defined by Eq. (4):

$$
\begin{aligned}
\text { Objective function : } \Theta & =\sum_{i=1}^{n_{1}}\left(\frac{a_{i} y_{i} z_{i}}{x_{i} r_{i}^{\beta}+\varepsilon}\right)^{\lambda_{i}}, \\
\text { s.t. } n_{1}=1,2,3 \ldots 7, \lambda_{i} & =\left\{\begin{array}{c}
-1, \text { if } \varphi_{i}>\varphi_{0} \\
1, \text { if } \varphi_{i}<\varphi_{0}
\end{array}\right.
\end{aligned}
$$

Where $\Theta$ is the functional region affecting index (Chen and Song, 2012), which was set as the total income of all TVEs in the 7 industry sectors $\left(n_{1}\right)$ of the Beijing suburbs; $x_{i}$ indicates the number of enterprises in industry sector $i ; y_{i}$ indicates the average income of industry sector $i ; z_{i}$ indicates the number of employees in industry sector $i$; and $x_{i}, y_{i}$ and $z_{i}$ indicate their simulation values, respectively. The distance between every county is $r_{i}$. $\alpha, \beta$ and $\eta$ are parameters. $\lambda_{i}$ is the output elasticity factor, which is designed via a two-state representation, as given in Eq. (1). $\varphi_{i}$ is the income of all TVEs in the ith industry sector, and $\varphi_{0}$ is the extremum of all TVEs in the ith industry sector. $n_{i}$ indicates the $i$ th industry sector, and $\varepsilon$ indicates the residual. Equation (1) shows that under conditions of total profit, all industries less than the extremum, the total profit of the entire region and the average income of industry sector $i$, the number of employees in industry 
sector $i$ has a positive correlation; additionally, there is a negative relationship between the total profit, the number of the enterprise $\left(x_{i}\right)$ and the spatial distance $\left(r_{i}\right)$. The purpose of Eq. (1) is to seek the extreme value under the conditions described above. We used the commercial software MATLAB for $\mathrm{VP} \mu \mathrm{GA}$ programming (Chen, 2016), and $x_{i}{ }^{*} z_{i}$ was taken as the industrial scale. A series of assumptions for mathematical modelling, simulation result cheques and validation of actual socioeconomic conditions were performed. One of the simulations is shown in Table 2 (this will be explained in the section on industry-region integration and examination, and it was also verified by tests). We refer the reader to a study by Chen for the specific mathematical process (Chen and Song, 2012); in this paper, we focused on using its conclusions to analyse regional development.

\section{Simulation results.}

(i) Agriculture-related industry: The encouragement of enterprises and the growth of the benefits of enterprises (see unit grids 2-5 at line 2 in Table 2) are inducements to rural labour. However, as the income of employees remains the lowest among the 7 industry sectors, the number of agriculture-related industry employees decreased. In other words, even though some farmers stayed in the agriculturerelated industry, the number of employees in other sectors of the industry increased. As a result, the migration of workers from rural to urban and agricultural to non-agricultural settings increased; and the industrial scale of the agriculturerelated industry tended to decrease. Thus, agriculture in the Beijing suburbs had to transform, and nonagriculturalisation was the general trend of development.

(ii) Industry: The number of industrial enterprises decreased. However, the sector's benefits increased rapidly, indicating that it shifted from scaled development to intensive development. This imposed greater pressure on TVEs. Therefore, the development of small and medium enterprises was reduced; the income of employees was the highest among those in the 7 industry sectors; the number of employees tended to increase; and the industrial scope tended to expand.

(iii) Construction: The number of construction enterprises decreased sharply. The sector's benefits and the income of employees remained at an intermediate level. The sector's scale tended to be reduced because most farmers in the Beijing suburbs were reluctant to engage in this industry. The increase in young farmers in Beijing has altered the basis of socioeconomic development of the Beijing suburbs.

(iv) Transportation: The number of transportation enterprises decreased sharply; however, the sector's benefits increased, and the income of employees was the second-highest among the 7 industry sectors. However, the sector's scale tended to decrease. The individual economic behaviours of the farmers in Beijing suburbs became increasingly important.

(v) Wholesale and retailing: The number of enterprises in this sector increased by approximately $1 / 3$; the sector's benefits ranked 6th among the 7 industry sectors; and the income of employees ranked 2nd. However, the scale tended to grow. Thus, on the one hand, the consumption level of the population improved; on the other hand, the sector still remained at the scale-increasing stage in 2008. Such small economic entities can operate more flexibly and adapt to changes in the external environment dictated by the urban economy. (vi) Retailing and catering: Enterprises in this sector increased by over one-fold; however, the number of employees decreased slightly. The sector's benefits also increased rapidly and the scale of the sector grew. This might be due to the flat high-end consumption of this sector and the rapid growth of low-end mass consumption. These results suggest a better chance for investors in the Beijing suburbs, and will facilitate an increase in the socioeconomic functions of the wholesale and retailing industry.

(vii) Household services: Enterprises in this sector decreased slightly. Its income was only higher than that of the agriculture sector; the number of employees reduced slightly and the sector's benefits dropped sharply. However, the sector's scale remained stable, thanks to the rigid demands of consumption. Seen from the actual conditions in Beijing, the pressure in this sector is mainly from the growing competitive strength of other cities.

Based on this preliminary analysis, the development scale of 7 industry sectors can be ranked as follows (in descending order): retailing and catering $\rightarrow$ wholesale and retailing $\rightarrow$ industry $\rightarrow$ household services $\rightarrow$ transportation $\rightarrow$ construction and the agriculture-related industry. The basic situation of the industry sectors and regional economic evolution is dictated by the development of TVEs and their employees. The simulation results in Table 2 are close to the actual conditions of the 7 industry sectors in 2008 .

\section{Analysis of results.}

(i) Industrial benefits and evolution: As seen in the simulation results, TVEs engaged in construction, industry and retailing and catering have greater benefits (Table 2). Therefore, the scale of the first two sectors is growing, though the number is decreasing. In the Beijing suburbs, the reduction in township construction enterprises and industry may be related to the fact that they are gradually moving on from disordered development and rapid growth. The immediate result is the increase in large and medium-sized enterprises and the decrease in the quantity and income of medium and small-sized TVEs. As a result, the influx of rural labour is reduced, and the labour must meet higher quality standards; these factors are consistent with the trend towards scaled and intensive development. Agriculture-related enterprises are experiencing an advantageous state. Incomes in this sector ranked 4th among the 7 industry sectors. The development of the transportation sector still depends on the employees' own efforts, and the scale of enterprises has not grown. The overall benefit of household enterprises is lower than average, and therefore the variation in enterprises and employees is small, reducing the sector's attractiveness to rural labour. The overall benefit of wholesale and retailing is average among the sectors, indicating that incomes are relatively stable. Additionally, the variation in the number of employees in the enterprises listed in Table 2 generally verifies the simulation results for the 7 industry sectors described above. To summarise the above analysis with regard to investment, the order of incomes in the sectors incomes is as follows (in descending order): construction and industry $\rightarrow$ retailing and catering $\rightarrow$ agriculture, wholesale and retailing and household services $\rightarrow$ transportation. Investors choose to enter or leave a sector or expand the enterprise scale accordingly, which means that free job selection based on maximum income became popular based on the guidance of the market. 
Table 3 Simulation Sample 1

\begin{tabular}{|c|c|c|c|c|c|c|c|}
\hline & Chaoyang & Fengtai & Haidian & Mentougou & Fangshan & Tongzhou & Shunyi \\
\hline Enterprises (number) & 680 & 895 & 3,208 & 9,891 & 39,589 & 23,826 & 25,368 \\
\hline Employees (number) & 51,967 & 59,252 & 62,206 & 30,122 & 285,884 & 211,286 & 213,558 \\
\hline \multirow[t]{2}{*}{ Corporate benefit ratio } & 53,273 & 33,429 & 48,710 & 30,046 & 31,931 & 25,793 & 40,154 \\
\hline & Changping & Daxing & Huairou & Pinggu & Miyun & Yanqing & \\
\hline Enterprises (number) & 2,661 & 27,930 & 8,939 & 4,050 & 12,660 & 7,214 & \\
\hline Employees (number) & 80,785 & 174,984 & 49,800 & 62,278 & 80,874 & 33,606 & \\
\hline Corporate benefit ratio & 30,914 & 40,978 & 33,211 & 25,157 & 25,409 & 25,826 & \\
\hline
\end{tabular}

(ii) Income and migration of employees: The information on benefit growth and the number of employees in the enterprises listed in Table 2 can be converted into simulated values of employee income after processing. From this perspective, the order of employee income is as follows (in descending order): industry and transportation $\rightarrow$ wholesale and retailing and construction $\rightarrow$ retailing and catering $\rightarrow$ household services and agriculture. Because the overall wage level of the industry sector ranked first among the 7 sectors, its number of employees increased. Although the number of transportation enterprises decreased, the income of employees increased (ranking 2nd), and the number is also growing. The employees in agriculture-related enterprises (ranked 7th) and wholesale and retailing (ranked 3rd) decreased slightly. The employees in retailing and catering (ranked 5th) decreased greatly, which might be due to the decrease in income based on the sector's characteristics and its expansion in scale. The number of employees in construction (ranked 4th) and household services (ranked 6th) was relatively stable. In short, compared with the analysis of industrial benefits and evolution in Section 'Industrial structure simulation', there is a discrepancy between the income of investors and employees. This discrepancy originated in the average employee scale (or the threshold of staff scale, as stated in Assumption (ii)) shown in the industrial structural simulation of enterprises in different industry sectors. Therefore, this sector is always the preferred choice for both.

(iii) Basic patterns of spatial distribution of industries: With respect to distance from the built-up urban areas, the spatial distribution of each sector's centre in the simulation results is as follows (see the last column in Table 2): wholesale and retailing $(3.82 \mathrm{~km}) \rightarrow$ household services $(9.43 \mathrm{~km}) \rightarrow$ construction $\quad(28.42 \mathrm{~km}) \rightarrow$ transportation $(35.43 \mathrm{~km}) \rightarrow$ retailing and catering $(40.15 \mathrm{~km}) \rightarrow$ industry $(45.64 \mathrm{~km}) \rightarrow$ agriculture $(54.81 \mathrm{~km})$. These results indicate that the industry sectors engaged in production of consumer goods (wholesale and retailing, household services) are usually located in nearby suburbs. The industry sectors immediately serving urban social functionalities are usually located in the inner circle of suburbs, and those not serving urban social functionalities are usually located in the outer circle of suburbs. Given the homogeneity of retailing and catering, the sector's centres are usually located in the middle circle of suburbs. The spatial distribution of the above 7 sectors matches the basic framework of the urban and rural function planning of Beijing (Fig. 5). However, this analysis is still preliminary. The spatial analysis and the industrial structure analysis will be performed during the development process of the 13 counties in the Beijing suburbs (Section 'Reginal development simulation'). The above analysis suggests that marketbased mechanisms (at the micro- to meso-scale) are in operation given that the TVEs and employees are driven by profits.

\section{Regional development simulation}

Simulating the evolution of regional development is complex. The simulation results can be accepted as correct only if they meet various conditions. Therefore, the final part of the industrial structure simulation must meet the requirements of the regional spatial change simulation.

The interconnections between the industries, TVEs and employees based on the market economy cannot fully reflect the development mechanisms of Beijing suburbs. During the region's development process, the momentum of industrial planning, the layout of urban and rural functions and other factors dictated by the government also act as significant driving factors. Based on TVE data for 2008, the industrial development of Beijing suburbs was analysed in Section 4. The results showed an optimising process of various economic activities with a remarkably static nature. However, these results cannot fully reflect the meso- to macro-scale spatio-temporal evolution of the Beijing suburbs. To understand the spatio-temporal evolution of the suburbs over the course of regional development and influenced by TVEs, this study further simulated evolution based on several different scenarios (corresponding to different development periods).

As seen from the representation of features in simulation sample 1 (Table 3 ), it is not easy to achieve an ideal simulation result. This is because the regional transition process involves a fitting process for each factor, and each fitting process, in turn, corresponds to a different development stage. We plot a diagram (Fig. 5) showing the evolution of the urban and rural functions by reference to previous studies (Qiu, 2005; Liu and Zhu, 2006; Tan and Zhu, 2007; Wang and Lu, 2005; Liang and Chu, 2005; Song and Wang, 2007); we use these studies to predict the possibility of each scenario. We followed this process because the 7 industry sectors in which the TVEs function not only play a role in the economy, but also undertake social service, ecological building and other functions in the Beijing suburbs. In this case, we choose the sample from Table 2; an explanation is given in Section 'Industry integration and examination'. The spatial distribution should also correspond to the distribution of the 13 suburban counties (Qi and Zhang, 2007; Zhang and Zhao, 2007).

Assumptions for modelling. In addition to the assumptions described in Section 'Industrial structure simulation', the statistical scope was expanded to the 7 industry sectors and 13 counties. We propose three assumptions as follows:

(i) The distribution of TVEs complies with the counties' distribution.

(ii) The benefit ratio is represented by the average income of employees in the counties.

(iii) The investors and employees may enter and leave a sector freely, but the overall benefit of the counties remains stable; 
Table 4 Average economic benefit ratio of the township enterprises in 13 Suburban Counties.

\begin{tabular}{|c|c|c|c|c|c|c|c|}
\hline & Chaoyang & Fengtai & Haidian & Mentougou & Fangshan & Tongzhou & Shunyi \\
\hline Enterprises (number) & 680 & 895 & 3,208 & 9,891 & 39,589 & 23,826 & 25,368 \\
\hline Employees (number) & 51,967 & 59,252 & 62,206 & 30,122 & 285,884 & 211,286 & 213,558 \\
\hline \multirow[t]{2}{*}{ Benefit ratio of enterprise } & 53,273 & 33,429 & 48,710 & 30,046 & 31,931 & 25,793 & 40,154 \\
\hline & Changping & Daxing & Huairou & Pinggu & Miyun & Yanqing & \\
\hline Enterprises (number) & 2,661 & 27,930 & 8,939 & 4,050 & 12,660 & 7214 & \\
\hline Employees (number) & 80,785 & 174,984 & 49,800 & 62,278 & 80,874 & 33,606 & \\
\hline Benefit ratio of enterprise & 30,914 & 40,978 & 33,211 & 25,157 & 25,409 & 25,826 & \\
\hline
\end{tabular}

The low-level non-agricultural development indicates that employees will return to rural areas to resume farming work, and the agricultural development has a robust development trend, and vice versa. The development states of the 13 counties in 2008 are used to represent the current state of development (Table 4).

Model specifications. The fitting process of the 7 sectors in the 13 counties was related to the income levels of enterprises and employees, as well as to land use. To simulate the industrial structure reflected by the fitting of enterprises and employees in the 13 suburban counties of Beijing, the following objective function was established in Eq. (5):

$$
\begin{gathered}
\Theta=\sum_{i=1}^{n_{2}}\left(\frac{a_{i} y_{i} z_{i}}{x_{i} r_{i}^{\beta}+\varepsilon}\right)^{\lambda_{i}} \text {, s.t. } n_{2}=1,2,3 \ldots 13, \\
\lambda_{i}=\left\{\begin{array}{c}
-1, \text { if } \varphi_{i}>\varphi_{0} \\
1, \text { if } \varphi_{i}<\varphi_{0}
\end{array}\right.
\end{gathered}
$$

Similar to Eq. (4), $\Theta$ is the total income of all the TVEs in the 13 counties (note that $\mathrm{n}_{2}$ differs from $\mathrm{n}_{1}$ in the industrial structure simulation) of the Beijing suburbs. All other variables, parameters and tests are as provided in Section 'Assumption and model specifications'. The quantity for each district was mainly determined based on the simulation industry and practitioners, and the spatial pattern and average revenue generated reflected the 13 counties and the 7 sectors. These factors will maximise the overall effectiveness of the conditions of the TVE development trend.

Based on analysis using the objective function given in Eq. (2), we further examined the overall development trend of the Beijing suburbs based on the $\mathrm{VP} \mu \mathrm{GA}$ simulation results and relevant evaluation indexes by adding the power function's trend line for the 13 suburban counties. According to the power function's trend line, the study assumed that the enterprises had sound economic benefits (in Scenario 1, the Growth Scenario; the trend is decreasing), the overall trend was stable (Scenario 2, the Conservative Scenario; the trend is stable) and the overall benefits decreased (Scenario 3, the Recession Scenario; the trend line is increasing). Other scenarios (such as the trend line having a complex shape) were rejected based on the actual situation, so as to represent the spatial coupling and relationships among the TVEs and employees in the 13 counties under different development states.

In this paper, we choose between these three development scenarios based on the development background. Spatial development in the Beijing suburbs experienced large expansion in the 1980 s and 1990s, then shifted to development in enclaves (industrial) and changed in type (urban) after 2000; currently, development is occurring in a radiating pattern with clumps and
Table 5 Simulation result sample (Scenario 1)

\begin{tabular}{llll} 
& $\begin{array}{l}\mathbf{x}_{\boldsymbol{i}} \text { - Calculated } \\
\text { value }\end{array}$ & $\begin{array}{l}\boldsymbol{y}_{\boldsymbol{i}} \text { - Calculated } \\
\text { value }\end{array}$ & $\begin{array}{l}\mathbf{z}_{\boldsymbol{i}} \text { - Calculated } \\
\text { value }\end{array}$ \\
\hline Chaoyang & 772.8665 & 54866.32 & 89082.47 \\
Fengtai & 1413.302 & 33582.26 & 79600.93 \\
Haidian & 2730.146 & 50038.15 & 68407.25 \\
Mentougou & 12492.78 & 54426.75 & 18966.53 \\
Fangshan & 44856.66 & 25460.33 & 423000.7 \\
Tongzhou & 26562.99 & 26074.15 & 205553.7 \\
Shunyi & 22310.69 & 45442.06 & 231666.5 \\
Changping & 2208.405 & 61146.6 & 98377.34 \\
Daxing & 28592.36 & 39204.69 & 78739.63 \\
Huairou & 10291.1 & 2545.789 & 23894.24 \\
Pinggu & 3046.33 & 24449.39 & 32790.25 \\
Miyun & 14785.55 & 25273.16 & 31899.32 \\
Yanqing & 14895.64 & 42198.9 & 14624.03 \\
\hline
\end{tabular}

fans. Therefore, the three development scenarios corresponding to this development background are as follows: (1) greater urbanisation and industrialisation processes during the early evolution of the current domain (including ecological, social, economic, and landscape processes); the urban-rural integration process and an increase in spatial extent; (2) urban and rural areas moving from the centre to the periphery during the early evolution of a single feature, showing a gradually decreasing trend on multiple levels; and (3) since 1978, the region has presented an evolutionary trend from simple to complex and from order to chaos.

Scenarios and simulation results. According to previous evaluation principles and studies on the Beijing suburbs (Liu and Zhu, 2006; Qi and Zhang, 2007; Song and Liu, 2011; Song et al., 2013a; Zhang and Gong, 2007) (Fig. 5 is one of its bases), the results are not consistent with previous conclusions. Some facts were rejected from the solution set of the $\mathrm{VP} \mu \mathrm{GA}$ simulation to make a feasible solution that complies with reality. Therefore, following the analysis, simulation results were selected for the following three scenarios, as shown in Tables $5-7$, in which, $x_{\mathrm{i}}$ indicates the number of enterprises in county $i$; $y_{i}$ indicates the average income of county $i$; $z_{i}$ indicates the number of employees in county $i$ :

(i) Scenario 1 (Growth Scenario): The simulation results of this scenario are presented in Table 5. The analysis showed that (1) the overall development of TVEs in the inner suburbs is high; and the increase in the number of employees indicates that the overall scale of the TVEs is expanding (see lines 2-5 in Table 5). However, some simulation results indicate that the development of TVEs is unbalanced and highly variable in Chaoyang, Haidian and Fengtai. Agricultural development is strong in these areas. (2) The number of TVEs of the mid-suburbs increased or decreased, and the amplitudes of the variations were smaller than for the 
Table 6 Simulation result sample (Scenario 2)

\begin{tabular}{|llll|} 
& $\begin{array}{l}\boldsymbol{x}_{\boldsymbol{i}} \text {-Calculated } \\
\text { value }\end{array}$ & $\begin{array}{l}\boldsymbol{y}_{\boldsymbol{i}} \text { - Calculated } \\
\text { value }\end{array}$ & $\begin{array}{l}\boldsymbol{z}_{\boldsymbol{i}} \text { - Calculated } \\
\text { value }\end{array}$ \\
\hline Chaoyang & 707.6108 & 33475.71 & 59769.14 \\
Fengtai & 540.6094 & 34091.95 & 67743.56 \\
Haidian & 2292.431 & 51018.69 & 62777.66 \\
Mentougou & 9804.28 & 29627.97 & 32561.26 \\
Fangshan & 40143.28 & 17375.35 & 297380 \\
Tongzhou & 24090.02 & 23972.71 & 228048.1 \\
Shunyi & 24411.09 & 44046.13 & 151586.4 \\
Changping & 318.0072 & 27676.15 & 87114.7 \\
Daxing & 27062.9 & 39564.88 & 187052.8 \\
Huairou & 9532.362 & 34132.71 & 53274.73 \\
Pinggu & 6601.755 & 31442.38 & 65047.81 \\
Miyun & 10914.74 & 11179.62 & 86207.5 \\
Yanqing & 4188.066 & 29867.08 & 18038.4 \\
\hline
\end{tabular}

Table 7 Simulation result sample (Scenario 3)

\begin{tabular}{llll} 
& $\begin{array}{l}\boldsymbol{x}_{\boldsymbol{i}} \text {-Calculated } \\
\text { value }\end{array}$ & $\begin{array}{l}\boldsymbol{y}_{\boldsymbol{i}} \text { - Calculated } \\
\text { value }\end{array}$ & $\begin{array}{l}\mathbf{z}_{\boldsymbol{i}} \text { - Calculated } \\
\text { value }\end{array}$ \\
\hline Chaoyang & 17.76924 & 39466.72 & 23374.71 \\
Fengtai & 513.0934 & 19491.27 & 61855.96 \\
Haidian & 2432.851 & 8629.066 & 41952.25 \\
Mentougou & 7765.252 & 26840.68 & 42459.19 \\
Fangshan & 36767.07 & 61707.1 & 347964.5 \\
Tongzhou & 26891.1 & 24963.63 & 145600.8 \\
Shunyi & 28975.35 & 57800.39 & 240047.3 \\
Changping & 2673.101 & 25405.47 & 63602.76 \\
Daxing & 10736.18 & 10585.58 & 142863.5 \\
Huairou & 10276.12 & 33171.4 & 58652.83 \\
Pinggu & 3905.766 & 24508.04 & 55778.27 \\
Miyun & 10277.02 & 27135.41 & 115881.7 \\
Yanqing & 6064.128 & 24742.11 & 56568.39 \\
\hline
\end{tabular}

previous results. However, the momentum of regional development was favourable. (3) The development of TVEs and agriculture in the outer suburbs was slightly less than in the mid-suburbs, and the number of TVEs also changed dynamically. However, many simulations indicated that the overall development of TVEs in some counties may be better with respect to the latter two functional areas.

$x_{i}$ indicates the number of enterprises in county $i ; y_{i}$ indicates the average income of county $i ; z_{i}$ indicates the number of employees in county $i$

On the whole, the Growth Scenario is consistent with both the centralised development state of the Beiiing suburbs and the rapid 'pancake-style' variability at the end of the 20th century and the beginning of the 21 st century. In addition, it is consistent with the power function's trend line given that the regional development from downtown to exurb areas is slowing; this is historically true for the urban-rural integration of the Beijing suburbs.

(ii) Scenario 2 (Conservative Scenario): The simulation results are provided in Table 6 . The analysis showed that (1) the inner suburbs had a strong development trend, but the number of TVEs increased or decreased. (2) The trend of agricultural development in the mid-suburbs and outer suburbs was improved relative to the current situation. The number of TVEs increased or decreased, showing dynamic changes. Additionally, the simulation results also indicated that development in the outer suburbs of some regions may be promising. This result suggests superior development relative to Scenario 1 (Growth Scenario).
The simulation results for the Conservative Scenario indicated that the TVEs in the Beijing suburbs are characterised by a disordered development state. This state is apparent in the small differences between regions, but also in the irregularity of development among different counties. The Beijing suburbs are currently shifting from decentralised middle to low-end industries (with extensive growth) to industrialised suburban economies (intensive growth), and this usually leads to a disordered state. Some TVEs (e.g., construction and recreation enterprises) may develop abnormally at this stage. We argue that the Conservative Scenario is consistent with the development state of Beijing suburbs during this period.

(iii) Scenario 3 (Recession Scenario): As shown in the simulation results provided in Table 7, (1) the benefits and number of TVEs decrease in the inner suburbs in this scenario. (2) Although the TVEs in the mid-suburbs experienced slightly improved conditions relative to those in the inner suburbs, their benefits also decreased. In contrast, the benefits, quantity and employees of enterprises in the outer suburbs increased.

The Recession Scenario corresponded to two development states: (1) The recession of the urban economy and the socioeconomic development supported by the agricultural economy. In this state, the benefits of TVEs in the inner suburbs and mid-suburbs are lesser due to the economic recession; meanwhile, agriculture and small enterprises strengthen as employees return to their hometowns to take up farming work. At present, it is improbable for such scenarios to take place. (2) The post-industrial development model for the social and ecological functions of Beijing suburbs was enhanced. Because Beijing is a metropolis, its social and ecological functions may develop rapidly, and it does not tend to merely pursue economic development; the middle to low-end, high energy-consumption and heavy pollution industries will also be phased out. Based on the actual situation of the Beijing suburbs, the 2nd development state was adopted in this paper.

General analysis. As shown in the above 3 scenarios (corresponding to different stages) of the development of TVEs in the Beijing suburbs, the inner suburbs are still the region where most employees are concentrated; the number and benefits of the enterprises are greater and they feature high risk and high incomes. As representatives of the market economy, TVEs may reflect the development of the non-agricultural industry in the suburbs. However, we also argue that the mid-suburbs are the most stable region for the development of non-agricultural enterprises (including the quantity and benefits). Since 1978, due to the influence of regional development, enterprises have tended to transit from extensive to intensive growth, and their number of employees usually decreases. The quantity and benefits of TVEs in the outer suburbs increased slightly relative to the mid-suburbs and the decrease in the number of employees was smaller (the process of intensive growth was slower). From the macro-scale view of regional development, the overall trend simulated by $\mathrm{VP} \mu \mathrm{GA}$ is consistent with reality. However, all 3 scenarios showed were abnormal development phenomena of TVEs in individual counties. Various features of the micro-scale economy, including disorder, local variations, and dynamic changes are now included.

It is important to note that Beijing's farmland and rural residential spatial distribution already have fractal characteristics (Song and Liu, 2012a; Song et al., 2013a). As a whole, Beijing's evolution proceeds in both a regular and an irregular manner. We suggest that the non-agricultural industries in Beijing's suburbs are more complicated and their fractal dimensions are greater than those of farmland or rural residential areas. A more in-depth 
Table 8 Comprehensive evaluation on the income of non-agricultural employees in 13 Counties of Beijing in 2007

\begin{tabular}{lllllll} 
Counties & Chaoyang & Fengtai & Haidian & Mentougou & Fangshan & Tongzhou \\
\hline Evaluation & 105.76 & 102.25 & 109.02 & 97.93 & 98.19 & 98.25 \\
Counties & Changping & Daxing & Huairou & Pinggu & Miyun & 98.39 \\
Evaluation & 99.05 & 98.74 & 97.67 & 97.64 & 97.66 & 97.44 \\
\hline
\end{tabular}

analysis should be conducted for the seven industries, their employees, and benefits and income. However, we focused our indepth study of the temporal evolution of Beijing's TVEs on their spatial complexity. This complexity includes understanding the spatial and temporal evolution of Beijing TVEs and their characteristics, which are important issues.

\section{Industry integration and examination}

Practically, it is hard to completely rely on mathematical simulations, which must be comprehensively analysed both quantitatively and qualitatively. Although the analysis in Section 'Industrial structure simulation' meets the preconditions of the industrial structure and regional development scenarios and can be objectively explained, it is still a mathematical simulationbased analysis. Therefore, further analysis should proceed using a multi-objective decision-making process.

The enterprises and employees and their spatio-temporal evolution may reflect the development of the industrial structure of Beijing suburbs (Wang and Lu, 2005; Richard and Michael, 2008; Tan and Volker, 2009). Because the economic function is integrated with the social and ecological functions also performed by the Beijing suburbs (Fig. 4), the results of the above industrial and regional development simulations inevitably include the transposition of multiple functions. This complexity may be why the Beijing suburbs shifted from Scenario 1 (Growth Scenario) to Scenario 3 (Recession Scenario).

Basic examination of scenarios. The employment situation of the industries was analysed using a survey of 3,000 farmers and the operating income of rural households of Beijing in 2008 (Beijing Municipal Bureau of Statistics, 2008). (1) Income from the tertiary sector is the main reason for the differences between the household incomes of farmers. Together with the income from secondary sectors, this forms the main income source for farmers in the Beijing suburbs, indicating that non-agricultural industry has become the main driving force of regional development. (2) Agricultural income is the second reason for the differences between the incomes of farmers. The differences between income groups was smaller than in the tertiary sector. The above analysis verifies that non-agricultural industries dominate the Beijing suburbs and result in the situation simulated in Scenarios 1-3.

Second, because non-agricultural income is the main income of employees, we carried out main components analysis on the 13 counties based on relevant data; this resulted in comprehensive evaluation scores (Table 8) of the wages of non-agricultural employees in each county. The results show that the Growth Scenario was generally consistent with the evaluation results, indicating that the Growth Scenario for agricultural development in the Beijing suburbs follows the 'pancake' development model of Beijing in 2008.

Spatial requirements for the transposition of industrial structures. According to studies by Tan and Liu (Tan and Zhu, 2007; Liu and Zhu, 2006), the buffer zone $30-40 \mathrm{~km}$ from downtown Beijing can be considered the boundary of the influence of the downtown area on the suburban areas (the transition from non- agriculture to agriculture zones); that is, the outskirts of the midsuburbs. The geographical significance of the buffer is shown by 3 aspects: (1) With respect to the suburban area within this buffer, economic activities are subject to or restricted by urban development. Business services, industry and other sectors are stronger relative to non-agricultural production activities. (2) Away from this buffer, the state of medium to small non-agricultural enterprises improves. Balanced economic development tends to occur between urban and rural areas. (3) Also away from this buffer, large-scale modern agriculture, recreational agriculture, ecological tourism and relevant retailing and catering, fruit production and other agriculture-related activities become the key components of regional economic activities, and ecological functions become the dominant factor in the development of the Beijing suburbs. The above analysis forms the basis of the industry layout in the industrial structural simulation.

The spatial transposition of such industrial structures is the result of the interaction among multiple parties (e.g., investors, enterprises, and employees) (Wilson, 2008, 2009). Objectively speaking, the spatial concentration and decentralisation of different industries and the migration of employees between various sectors requires narrowing the gap between urban and rural residents, facilitating regular transposition of urban and rural functions and avoiding disordered development. Thus, the development of TVEs in the Beijing suburbs must shift from Scenario 2 (Conservative Scenario) to Scenario 1 (Growth Scenario) in the industrial structural simulation.

In short, the above analysis was based on micro-scale and meso-scale analyses of the characteristics of TVEs and employees. We interpret the spatial features based on economic benefits, the foundation for the existence of Scenarios 1-3, and the rationality of Scenario 1 (Growth Scenario).

The profit and tax differences between non-agricultural enterprises. The profit and tax differences of enterprises in different locations can also reflect the industrial benefits and spatial patterns in the suburbs of Beijing. This also follows the analysis in Sections 'Industrial structure simulation' and 'Regional development simulation'. Based on the profits and taxation of nonagricultural enterprises in the suburban counties of Beijing, nonagricultural enterprises with a larger scale were analysed in this study by examining the enterprise size and taxes paid by employees. The trend analysis indicates that the development of larger enterprises (e.g., construction and industry) is closer to Scenario 3 (Recession Scenario). Relative to the actual situation, we argue that this does not mean a decline in the urban economy, but rather that larger non-agricultural industries are developing under a post-industrial development model and adjusting their economic functions to their social and ecological functions. Scenario 3 (Recession Scenario) applies to the actual situation of these enterprises.

Furthermore, smaller non-agricultural enterprises (e.g., retailing, common catering, and household services) were also analysed. The trend line indicates that these enterprises are developing under the model described in Scenario 1 (Growth Scenario), and have overcome the difficulties described in 
Scenario 2 (Conservative Scenario). This complies with the actual situation around 2008 .

\section{Discussion}

Evolution of the Beijing suburbs. Competition among industries and regions within the Beijing suburbs may cause restructuring of socioeconomic activities. The balance of existing socioeconomic structures will change when socioeconomic disparities reach threshold values reflecting the balanced development of urban and rural areas; they will again achieve a balanced state after adjustment processes. Thus, it is insufficient to analyse the evolution process of the Beijing suburbs within just one period. The entire evolutionary process must be considered to understand the formation, development and change of the industrial-spatial structure. Regarding spatial concentration and diffusion, the regional spatial structure can be analysed according to the flow of economic factors, especially the long-term trend.

Technical methodology. Regional development is a spatial coupled system involving social, economic and cultural fields and the possibility of multiple development states. One of the purposes of this study was to understand the background of regional development and the parameters that define the system based on mathematical principles, with the goal of achieving a scientifically-based understanding of this complex system. Therefore, the research objectives of this analysis have progressed beyond geographical space (such as the real space in the 13 suburban counties) to also include geographical concerns (such as the multiple states of industrial structure) associated with the state space (phase space).

\section{Conclusions}

Using the development of the TVEs in the Beijing suburbs as an example, this paper investigated the evolutionary process and state of this research objective using $\mathrm{VP} \mu \mathrm{GA}$ simulation. We also analysed the change in the spatial pattern of the TVEs and their employees based on economic interests (both actual and planned). The use of $\mathrm{VP} \mu \mathrm{GA}$ to analyse the various parameters allowed us to determine the industrial structure of Beijing's township enterprises in the presence of state services. We summarise the main conclusions of this study below.

Overall situation of regional development. First, it is evident from Tables 5, 6 and 7 that the balance among the benefits of counties and the incomes of employees is lost during the transition between scenarios. (1) The modern agriculture of the midsuburbs may lead to greater development; non-agricultural industries are also likely to increase as a result of the outward shift of the urban economy and the concentration of economic factors; however, development of this industry is restricted by ecological conditions and social functions. The traditional industries in the mid-suburbs will gradually shift outward. (2) The outer suburbs are similar to the mid-suburbs; however, their landscaping and recreation functions may bring greater profits to enterprises engaged in tourism, catering, hotels and so on. Furthermore, this may accelerate the development of the ecological economy system represented by green agriculture and characteristic agriculture.

Second, it can be seen from the coordinated micro-, meso- and macro-scale development that the socioeconomic foundation of Beijing suburbs has changed significantly since the 1980s. Nonagricultural enterprises and employees demonstrate this trend following a period of more disordered development. They indicate a certain spatial hierarchy and constitute the dominant force driving regional macro-development. Although such a multi-level structure is still subject to dynamic changes, it has created a favourable development environment for urban-rural integration. The situation is characteristic of the regional evolution of a variety of urban and rural spatial features.

Selection of macro-development path. The micro- and mesoscale analyses of the TVEs under different scenarios indicated the following: (1) Scenario 3 (Recession Scenario) reflects the development of larger non-agricultural industries and the dominant trend of non-agricultural industries in the Beijing suburbs. Intensive development is its basic feature. Scenario 2 (Conservative Scenario) was characterised by greater development of small and medium enterprises. Scenario 1 (Growth Scenario) reflected the overall development situation of the Beijing suburbs at present. (2) If the 3 scenarios are viewed as a possible development state of the Beijing suburbs, we argue that the development path should be as follows: Scenario 2 (Conservative Scenario) $\rightarrow$ Scenario 1 (Growth Scenario) $\rightarrow$ Scenario 3 (Recession Scenario). This is a realistic path for urban-rural integration based on multi-function development, because it includes the rapid development of the inner suburbs as well as the more steady development of the middle and outer suburbs, with multiple industrial centres and layers.

Spatial foundation and policy support for urban-rural integration. As shown in the simulation results, the lopsided development situation (especially the lag between the agricultural production and ecological functions) will remain unchanged, leading to a greater urban-rural gap if based solely on the market economy, and the development of the Beijing suburbs will be hindered. To avoid this outcome, regional planning should include strong support for urban-rural integration. As an international metropolis, Beijing should maximise the economic, social, and ecological functions of the suburbs, rather than mere economic growth, and use these features as the foundation of urban-rural integration. The government could then support key industries according to their functions in different areas of the 13 counties, aiming to drive rational allocation and balanced development of urban-rural functions.

The results of this study show that agriculture is the foundation for the development of the Beijing suburbs, and non-agricultural industries dominate its development. We argue that emphasis should be placed on small and medium enterprises to support their development and form industrial assemblages, which will promote non-agriculturalisation and regional economic development. This will lead to changes in industrial evolution, land use and social functions, and influence the transposition of urban and rural functions. Therefore, close attention should be paid to the future industrial evolution of the Beijing suburbs and its development should be planned carefully.

Our further research will focus on developing new types of CI algorithms and employing artificial intelligence driven design tool via CIAD framework to study multifractal characterisation of urban form and growth, and then to validate the models based on the big data of the city. To achieve the long-term spatio-temporal evolutionary mechanism for city planning in the future, more experimental research is expected to establish social, economic, and environmental coupled behaviours, in which the big data, such as geographical features, spatial distribution of populations and its social dynamical features, etc. are to be included.

Received: 12 October 2017 Accepted: 21 February 2018 Published online: 20 March 2018 


\section{References}

Allen PM, Sanglier M (1981) Urban evolution: self-organization and decisionmaking. Environ Plan A 13:167-183

Beijing Municipal Bureau of Statistics (2003) Statistical yearbook of Beijing, China Statistics. China Statistics Press, Beijing, 2011

Carlos A, Coello CC, Gregorio TP (2001) A micro-genetic algorithms for multiobjective optimization. Lect Notes Comput Sci 1993/2001:26-140

Chen Y (2016) Simple Genetic Algorithm Laboratory Toolbox for MATLAB (SGALAB 1003Beta 5.0.0.8), www.mathworks.com/matlabcentral/ fileexchange/5882. Accessed 10 Feb 2018

Chen Y, Li Y (2018) Computational intelligence assisted design (In the Era of Industry 4.0), CRC Press

Chen Y, Song ZJ (2012) Spatial analysis for functional region of suburban-rural area using micro genetic algorithm with variable population size. Expert Syst Appl 39:6469-6475

Chen YG, Wang JJ (2013) Multifractal characterization of urban form and growth: the case of Beijing. Environ Plan B 40(4):884-904

Clive P, Tilzey M (2007) Agricultural multifunctionality, environmental sustainability and the WTO: Resistance or accommodation to the neoliberal project for agriculture? Geoforum 38(6):1290-1303

Feng J, Zhou YX (2004) Intra-urban migration and correlative spatial behavior in Beijing in the process of suburbanization: based on 1000 questionnaires. Geogr Res 23(2):227-242

Goldberg DE (1989) Sizing populations for serial and parallel genetic algorithms. In Schaffer JD (ed) Proceedings of the Third International Conference on genetic algorithms, Morgan Kaufmann Publishers Inc., San Mateo, CA

Huang LS, Chen YG (2018) A comparison between two OLS-based approaches to estimating urban multifractal parameters. Fractals 26(1):1850019

Junichi I (2006) Economic and institutional reform packages and their impact on productivity: a case study of Chinese township and village enterprises. J Comp Econ 34(1):167-190

Krishnakumar K (1989) Micro-genetic algorithms for stationary and nonstationary function optimization. SPIE 1196:289-296

Liang JS, Chu B (2005) Urban Sprawland spatially interdependent development of Beijing: a analysis based on the Lowry Model. Urban Plan 29(6):9-14. 2005

Liu CX, Zhu Q (2006) Evaluating the geographic concentration of manufacturing industries of Beijing based on distance-based methods. Acta Geogr Sin 61 (12):1247-1258

Louis P (1997) On the past and future of China's township and village-owned enterprises. World Dev 25(10):1639-1655

Louise W, Peter HV (2008) Spatial characterization of landscape functions. Landsc Urban Plan 88(1):34-43

Meng Y, Zhang FR (2008) Industrial land-use efficiency and planning in Shunyi, Beijing. Landsc Urban Plan 85(1):40-48

Qi YH, Zhang FR (2007) Characteristics of input of suburban farmers of metropolises and variance analysis. Resour Sci 29(4):13-17

Qiu HJ (2005) Analysis and evaluation on the sustainability of the metropolis agriculture of Beijing. Beijing, China Agricultural University, Doctorial Dissertation, pp 43-127

Richard SL, Michael TH (2008) Generating sustainable towns from Chinese villages. J Environ Manag 87(2):305-316

Song JP, Wang ER (2007) Housing suburbanization and employment spatial mismatch in Beijing. ACTA Geogr Sin 62(4):387-396

Song ZJ, Liu LM (2010) Study on the functions and research method of modern suburban agricultural regions in China. J China Agric Univ 15(6):120-126

Song ZJ, Liu LM (2011) Spatial characteristics analysis for the multifunctional transition of Suburban agricultural areas in Beijing. Sci Geogr Sin 31 (4):427-433

Song ZJ, Liu LM (2012a) Study on the spatial structure of cultivated land in Beijing based on the spectrum and fractal characteristics. Geogr Res 31(8):1399-1410

Song ZJ, Liu LM (2012b) The process and enlightenment of Beijing urban-rural integration since 1988. Progress Geogr 31(8):1399-1410

Song ZJ, Guan XK, Zhu ZQ (2013a) Study on the spatial fractal characteristics and complexity of rural residential areas in Beijing. Sci Geogr Sin 32(12):52-60

Song ZJ, Zhu ZQ (2013b) Study on the temporal-spatial evolvement of structure in Beijing suburban agricultural spheres from 2000 to 2008. J China Agric Univ 18(1):202-209

Tan MH, Zhu HY (2007) Spatial patterns of built-up areas around Beijing. Acta Geogr Sin 62(8):861-869

Tan R, Qu FT (2011) Rural to urban land conversion in China-How large is the over-conversion and what are its welfare implications? China Econ Rev 22 (4):474-484
Tan R, Volker B (2009) Governing farmland conversion: comparing China with the Netherlands and Germany. Land Use Policy 26(4):961-974

Wang PF, Lu Q (2005) On the relationship between the spatio-temporal structure of agricultural land use changes and density of population in Beijing city from 1980 to 2000. Acta Geogr Sin 60(6):953-964

Wilson GA (2008) From 'weak' to 'strong' multifunctionality: conceptualising farm-level multifunctional transitional pathways. J Rural Stud 24(3):367-383

Wilson GA (2009) The spatiality of multifunctional agriculture: a human geography perspective. Geoforum 40(2):269-280

Zhang FR, Zhao HF (2007) Layout of metropolitan modern agriculture, China University of Petroleum Press, p 71-106 (in Chinese)

Zhang YQ, Gong HL (2007) Analyzing the mechanism of land use change in Beijing city from 1990 to 2000 . Resour Sci 29(3):206-213

Zhao SXB, Wong KeKK (2002) The sustainability dilemma of China's township and village enterprises: an analysis from spatial and functional perspectives. J Rural Stud 18(3):257-273

\section{Data availability}

The datasets analysed during the current study were derived from the following public domain resources

1. Township Enterprises Yearbook of Beijing 2007 https//www.amazon.cn/\%E5\%9B\%BE $\%$ E4\%B9\%A6/dp/B00KX0YU76

2. Beijing Statistical Yearbook 2007 http//www.bjstats.gov.cn/nj/main/2007/index.htm

\section{Acknowledgements}

The authors would like to acknowledge the partial supports provided by the The DGUT High-Level Talent Research Startup Grant (No. G200906-07, G200906-14). Also, the authors would like to acknowledge the anonymous reviewers with their valuable comments for this paper.

\section{Author contributions}

YC, Z-JS and G-FZ conceived the idea, Z-JS, G-FZ and YC provided the theoretical analysis, Z-JS, G-FZ and MTM wrote a major portion of the manuscript, Z-J S, G-FZ and YC performed the numerical simulations and prepared all the figures, YC and YL wrote a minor portion of the manuscript. All authors reviewed the manuscript.

Reprints and permission information is available online at http://www.nature.com/ reprints

Publisher's note: Springer Nature remains neutral with regard to jurisdictional claims in published maps and institutional affiliations.

\section{Additional information}

Competing interests: The authors declare no competing financial interests.

Reprints and permission information is available online at http://www.nature.com/ reprints

Publisher's note: Springer Nature remains neutral with regard to jurisdictional claims in published maps and institutional affiliations.

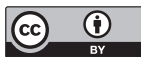

Open Access This article is licensed under a Creative Commons Attribution 4.0 International License, which permits use, sharing, adaptation, distribution and reproduction in any medium or format, as long as you give appropriate credit to the original author(s) and the source, provide a link to the Creative Commons license, and indicate if changes were made. The images or other third party material in this article are included in the article's Creative Commons license, unless indicated otherwise in a credit line to the material. If material is not included in the article's Creative Commons license and your intended use is not permitted by statutory regulation or exceeds the permitted use, you will need to obtain permission directly from the copyright holder. To view a copy of this license, visit http://creativecommons.org/ licenses/by/4.0/

(c) The Author(s) 2018 